\title{
Efficiency comparison of capacitive wireless power transfer for different materials
}

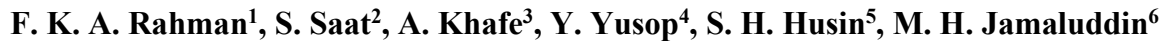 \\ 1,2,3,4,5 Centre for Telecommunication Research \& Innovation, Universiti Teknikal Malaysia Melaka (UTeM), Malaysia \\ ${ }^{6}$ Department of Electrical Engineering, Universiti Teknologi Malaysia, Malaysia
}

\begin{tabular}{l} 
Article Info \\
\hline Article history: \\
Received Apr 8, 2019 \\
Revised Aug 14, 2019 \\
Accepted Nov 3, 2019 \\
\hline
\end{tabular}

Keywords:

Aluminium material Capacitive power transfer Class E converter Copper material

Zinc material

\begin{abstract}
This paper describes the application of several types of materials to act as capacitive plates in a Capacitive Power Transfer (CPT) system. In general, the efficiency of CPT system is greatly influenced by the coupling capacitance which is varied by distances and permittivity values. Thus, this paper intended to compare the performance of CPT system in terms of the output efficiency for several types of capacitive plates. To be specific, copper plate, zinc, and aluminium are used in this work to act as coupling plates to the CPT system. The CPT system in this work applied class E inverter as it has lowest switching losses among its competitors, i.e. class D and class F. The work is validated through experimental setup of CPT system in which copper material provides the best efficiency of the system.
\end{abstract}

This is an open access article under the CC BY-SA license.

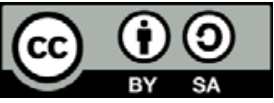

\section{Corresponding Author:}

Shakir Saat,

Faculty of Electronic and Computer Engineering,

Universiti Teknikal Malaysia Melaka,

Hang Tuah Jaya, 76100 Durian Tunggal Melaka, Malaysia.

Email: shakir@utem.edu.my

\section{INTRODUCTION}

Wireless Power Transfer researches have been going on for multiple decades. The major contribution of this area made by Inductive Power Transfer (IPT) which implement the usage of magnetics (inductors or cores) [1-3]. Other than IPT, Capacitive Power Transfer (CPT) and Acoustic Energy Transfer (AET) are also available [4-6]. CPT has been one of the major researches in building sustainable engineering system nowadays, as part of the encouraging development of wireless power transfer due to its strong antiinterference ability of the magnetic field [7]. The most significant difference of these types of wireless power transfer system is in terms of the coupling between transmitter and receiver side in which CPT uses electric field propagation $[8,9]$ while IPT uses magnetic field transfer $[10,11]$ and propagation of sound waves is the method used in AET $[12,13]$.

Despite of its reliability, the IPT system is having weaknesses which is unable to penetrate metal shielding due to low anti-interference ability of the magnetic field, and also larger eddy current produced by IPT thus indicate higher losses [14]. These issues are then enhanced by implementing CPT approach. In CPT, strong anti-interference is able to reduce energy loss and electromagnetic interference, a part from enabling the particular device to work in saturated or intense magnetic fields environment. The basic idea of a CPT system is as shown in Figure 1. 


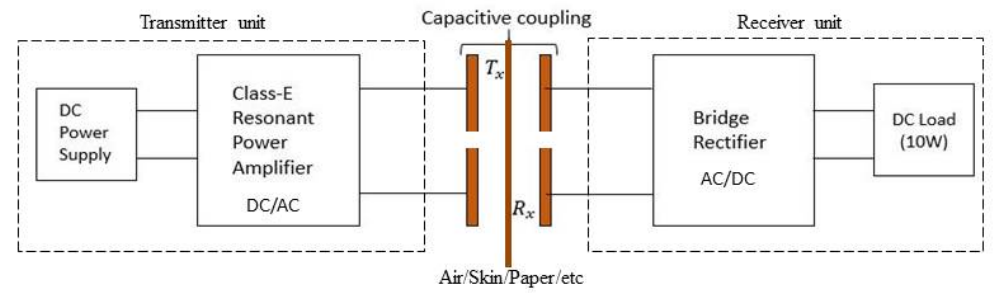

Figure 1. Basic CPT System with bipolar configuration

From Figure 1, CPT system consists of two major parts which are the transmitting unit and the receiving unit and is separated by a medium i.e. air/ skin/ paper/ etc. Building CPT system by using class E inverter is, at the moment, the most reliable method for higher frequency applications [13-15]. On top of that, this type of inverter is also used because of its simple topology and the ability to achieve very high efficiency in return. This is due to the Zero-Voltage Switching (ZVS) characteristics of class E which is able to produce $100 \%$ switching condition [16].

The most common configuration found in previous works is that the $\mathrm{C}_{1}$ and $\mathrm{C}_{2}$ are located parallel to each other to form bipolar configuration [17] which consists of two sets of transmitter and receiver plates $[14,18,19]$. The transmitter plates have been driven by a high frequency inverter with a 180-degree phase difference by a high alternating voltage. The receiver plates, on the other hands, are connected to the load. In Figure 1, when one primary plate is positively charged, the other primary plate has a negative charge and therefore phase altering potentials exists there. An alternating electric field produced by this process caused power to be delivered to the load.

Apart from its advantages, CPT is currently having major issue regarding the output efficiency as separation distance is increasing. In the previous work [20], the gap between the capacitive coupling need to be lesser than $1 \mathrm{~mm}$ for basic circuit configuration with class $\mathrm{E}$ inverter in order to achieve efficiency of $98.44 \%$. Besides, there was also a gap distance analysis which concluded that as distance increases, the efficiency of the system is tremendously decreases exponentially.

This work is delivered to perform performance comparison of different materials of the capacitive plates for the existing class E CPT system with an impedance matching circuit. Besides, this work is also done to validate the theory which mentioned the factors affecting the capacitance values are the plates area, plates distance, and dielectric materials [21]. To the authors' knowledge, to date, there is no result on the comparison of output efficiency of CPT system for different type of material available, instead most of them explained about the effect of outcomes based on different dielectric materials of the CPT system [9, 17, 22, 23]. Hence, this work aims to study the underlying problem and then to propose the best material to be applied in the framework of CPT system. The contributions from this paper can be summarized as follows: (i) this paper focuses on introducing different materials which are copper, zinc and aluminium as the alternatives to act as capacitive plates in a CPT system with Class-E resonant inverter topology and a $\pi 1$ a impedance matching network; (ii) the output voltage of the system can still be maintained over $50 \%$ from optimum values even after 10 pieces of papers were overlaid in between the plates. This indicates the reliability of each material chosen to be capacitive plates; (iii) the effects on performances' outcomes are analysed in terms of Zero-Voltage-Switching (ZVS) condition and output voltage and being compared for all three materials used.

Section 2 will be focusing on the background study, Section 3 is the experimental setup, Section 4 is about the experimental results, and the last section is concerning on the conclusion and the enhancement work for the future.

\section{BACKGROUND STUDY}

\subsection{Class $\mathrm{E}$ circuit configuration}

One important feature of the CPT system as highlighted in Figure 2 is class E circuit configuration. This type of circuit configuration consists of a power MOSFET operates as a switch, a $L-C-R_{i}$ series-resonant circuit, a shunt capacitor $C_{1}$, and a choke inductor $L_{f}[24,25]$.

The Class E circuit configuration has been introduced by The Sokals. It is utilized because of its simplicity and the basis of the circuit operation which includes the unique principles of load network operation to achieve better efficiency $[26,27]$. Figure 3 shows the power efficiency resulting from Class $\mathrm{E}$ circuit configuration. 


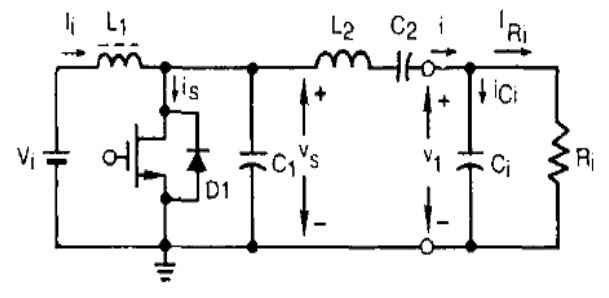

Figure 2. Class E circuit configuration

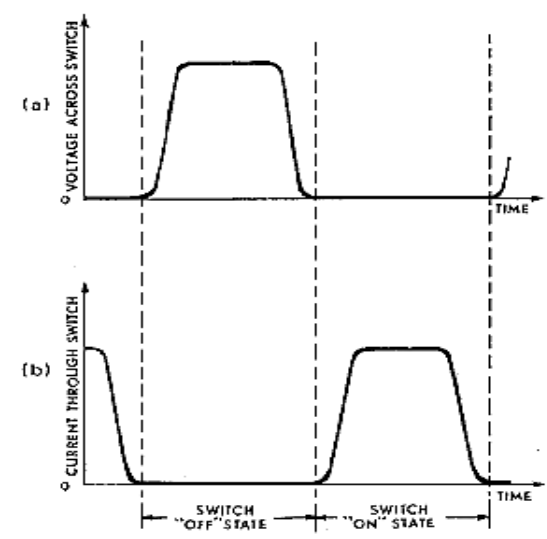

Figure 3. Optimum waveforms in Class E circuit for maximum power efficiency [26]

However, the waveforms of Figure 3 in which the delay is increasing from zero until the other waveform has completed decreasing to zero, may only be formed by appropriate design of a non-resistive load network. The efficiency of the results could then be in a proper increment if the transition time of the switch is in an appreciable fraction of a half-cycle of the AC waveform. Furthermore, the ZVS operation, as the class E switching condition, able to minimise the switching loss and leads the converter to have high converting efficiency even when the converter works at high frequency. Based on the theory, the class E amplifier can work from several megahertz to dozen of megahertz with a high-speed power transistor [28].

\subsection{Impedance matching circuit}

Impedance matching has been used to increase the amount of power extracted in a power conditioning circuit in [29]. Moreover, by using impedance matching, [18] succeed to achieve output efficiency as high as $95.44 \%$ while still able to produce a stable sinusoidal signal to drive the capacitive coupling based on flat rectangular copper plates, and operated at $1 \mathrm{MHz}$.

CPT system in this work used a $\pi$ la impedance matching circuit where a capacitor is added parallel to the load $\left(\mathrm{R}_{\mathrm{L}}\right)$. There are several types of matching outlined by [25] and one of them is by tapping the resonant capacitance $\mathrm{C}$ to accomplish the impedance transformation, as shown in circuit configuration of $\pi 1 \mathrm{a}$ impedance matching circuit in Figure 4. The complete circuit configuration of class E inverter with the $\pi 1 \mathrm{a}$ impedance matching network is given in Figure 5.

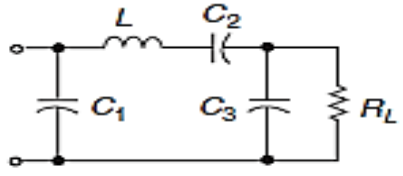

(a)

Figure 4. $\pi$ la impedance matching circuit [25]

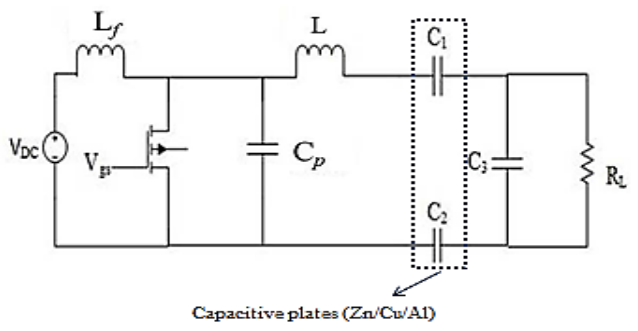

Figure 5. CPT system with class E inverter with $\pi 1 \mathrm{a}$ impedance matching network illustrated by MATLAB Simulink [18]

The reason of choosing this impedance matching is because it provides downward impedance transformation, and the added capacitor which is in parallel with the resistive load can maintain the efficiency of the circuit as series capacitor $\mathrm{C}_{2}$ later modified to capacitive coupling plates to fit the actual CPT system [27]. By using this circuit, the capacitor $C_{3}$ can be calculated by using equations described in [25], as follows: The series equivalent resistance $R_{S}$ is given by

Int J Pow Elec \& Dri Syst Vol. 11, No. 1, Mar 2020 : $200-212$ 


$$
R_{S}=\frac{8}{\pi^{2}+4} \frac{V_{I}^{2}}{P_{R i}} \approx 0.5768 \frac{V_{I}^{2}}{P_{R i}}
$$

The reactance factor, $q$ for the $R i-C_{3}$ and $R_{S}-C_{S}$ equivalent two-terminal networks is

$$
q=\frac{R_{i}}{X_{C_{3}}}=\frac{X_{C S}}{R_{S}}
$$

Furthermore, resistances $R s$ and $R i$ as well as the reactance $X_{C_{s}}$ and $X_{C_{3}}$ are also interrelated by

and

$$
R_{S}=\frac{R_{i}}{1+q^{2}}=\frac{R_{i}}{1+\left(\frac{R_{i}}{X_{C 3}}\right)^{2}}
$$

$$
X_{C S}=\frac{X_{C 3}}{1+\frac{1}{q^{2}}}=\frac{X_{C 3}}{1+\left(\frac{X_{C 3}}{R_{i}}\right)^{2}}
$$

Rearrangement of (3) yield to

$$
q=\sqrt{\frac{R i}{R s}-1}
$$

Meanwhile, substitution of (5) into (2) gives

$$
X_{C S}=R_{S} \sqrt{\frac{R i}{R S}-1}
$$

Later, one arrives at

$$
X_{C 2}=\frac{1}{\omega C_{2}}=\left[Q_{L}-\frac{\pi\left(\pi^{2}-4\right)}{16}-\sqrt{\frac{R i}{R s}-1}\right]
$$

From (2) and (5), we have

$$
X_{C 3}=\frac{1}{\omega C_{3}}=\frac{R_{i}}{q}=\frac{R_{i}}{\sqrt{\frac{R i}{R s}-1}}
$$

It follows from (8) that the resistances of circuit shown in Figure 4 can satisfy the inequality

$$
R_{s}<R_{i}
$$

Suboptimum operation is obtained for

$$
0 \leq R_{s(s u b)}<R_{S}
$$

This corresponds to

$$
R_{i} \leq R_{i(s u b)}<\infty
$$

Moreover, the amplitude of voltage across $C_{2}, V C_{2 m}$ can be determined by

$$
V C_{2 m}=X c_{2} I m
$$

\section{EXPERIMENTAL SETUP FOR CPT SYSTEM: DIFFERENT COUPLING PLATES}

The CPT system with impedance matching circuit is further utilized to analyse the effect of different types of capacitive plates as the transmitter and the receiver parts. This section describes the experimental

Efficiency comparison of capacitive wireless power transfer for different materials (F. K. A. Rahman) 
setup for different material of coupling plates. The specification for the system is tabulated in Table 1. Based on the specification in Table 1 and using equations given in previous section, the components values of the system is as listed in Table 2.

Table 1. Pre-determined specifications of class E CPT power amplifier

\begin{tabular}{cc}
\hline Specification & Value \\
\hline Output power, $\mathrm{P}_{\mathrm{o}}$ & $10 \mathrm{~W}$ \\
Input voltage, $\mathrm{V}_{\mathrm{i}}$ & $12 \mathrm{~V}$ \\
Duty cycle, $\mathrm{D}$ & 0.5 \\
Frequency, $\mathrm{f}$ & $1 \mathrm{MHz}$ \\
Quality factor, $\mathrm{Q}$ & 10 \\
\hline
\end{tabular}

Table 2. Values of components used for CPT circuit with $\pi$ la impedance matching network

\begin{tabular}{cc}
\hline Components & Value \\
\hline L $_{\text {choke }}$ & $100 \mu \mathrm{H}$ \\
CShunt $_{\text {SSeries }}$ & $52.1 \mathrm{pF}$ \\
CSeries $_{(}\left(C_{2}\right)$ & $60.3 \mu \mathrm{H}$ \\
$R_{L}$ & Capacitive coupling $0.15 \mathrm{~m} \mathrm{x} 0.16 \mathrm{~m}(2.44 \mathrm{nF})$ \\
Impedance matching $\left(C_{3}\right)$ & $18 \Omega$ \\
\hline
\end{tabular}

Furthermore, Figure 6 shows the experimental setup which consists of a MOSFET driver, a class E circuit, and the resistive load, $R_{L}$. The plates used in this work were placed on the bookends to ensure their stability and reliability to transfer power wirelessly. Apart from the CPT system, the experimental works done by using three different materials commonly available in the market, namely Zinc, Aluminium, and Copper, as shown in Figure 7.

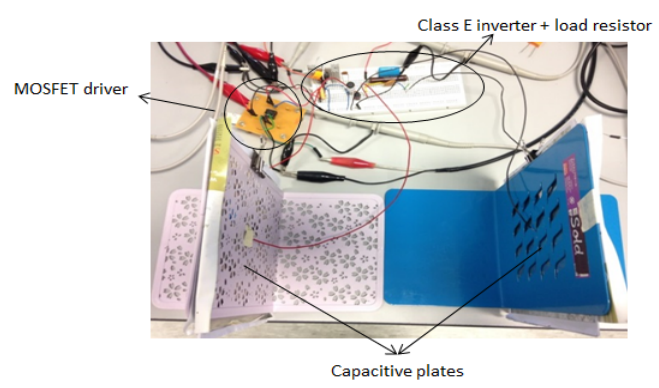

Figure 6. Experimental setup for the CPT system

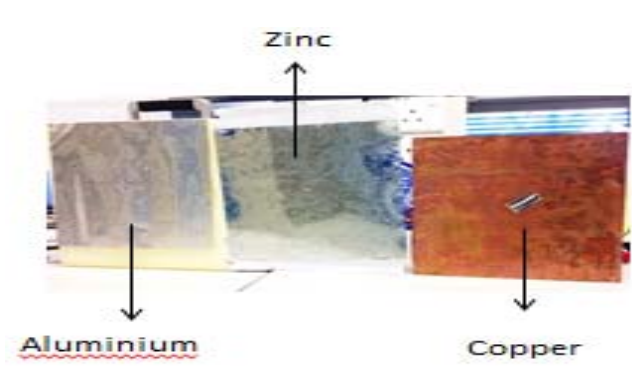

Figure 7. Different types of capacitive plates for aluminium, zinc, and copper

All of these plates are of same size; $0.16 \mathrm{~m} \times 0.15 \mathrm{~m}$. The size is maintained to ensure that the outcome of this work will only be based on different types of capacitive plates used. This work is furthermore, objectified to provide significant evidence that the output power will not be affected by the type of materials used for capacitive plates. As mentioned in [21], the value of capacitance of a circuit will be influenced by plates size, plates distance, and the dielectric materials used. In this work, the dielectric material used throughout the experimental work is an A4 paper. To increase gap distance between the plates, the sheet of paper is increased by one per reading, as shown in Figure 8. 


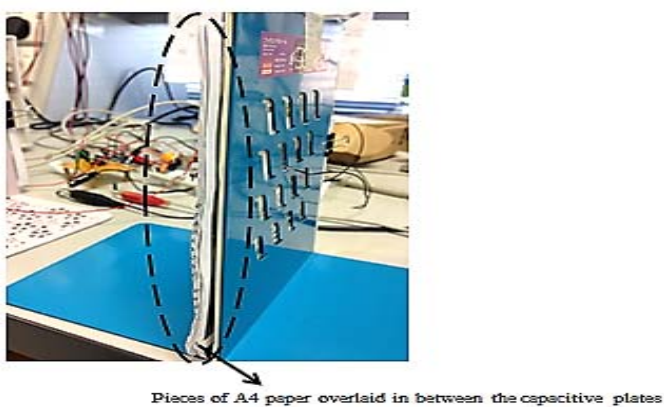

Figure 8. Sheets of A4 paper overlaid in between the capacitive plates (in circle)

Based on Figure 8, the A4 paper utilized is $70 \mathrm{gsm}$ which has thickness of $0.01 \mathrm{~mm}$, and placed in between both transmitter and the receiver part of the system. The paper, which has dielectric constant 2.0-2.5 $[23,30,31]$, represented dielectric material which is one of the factors that will affect the capacitance values. The particular capacitance value of the capacitive plates can be determined by using formula $C=\frac{A \varepsilon_{0} \varepsilon_{r}}{d}$ [22], whereby $d$ is the distance between the transmitter and the receiver plate, and $\mathrm{A}$ is the area of the capacitive plate which is fixed at $0.05 \mathrm{~m}^{2}$. Besides, $\varepsilon_{o}$ is a constant $\left(8.85 \times 10^{-12}\right)$, and $\varepsilon_{r}$ is the relative permittivity/dielectric constant of the material.

\section{EXPERIMENTAL RESULTS}

By using several different materials as the capacitive plates, the outcome of this work are analysed in terms of the Zero-voltage-switching (ZVS) condition and the output voltage of the system. These analyses are very important for verifying the work because since this system uses class E as the power amplifier, ZVS analysis being an important factor to be taken into account as it will determine the efficiency of the system. The operation of ZVS is highly sensitive with the circuit parameters (namely $L, C$ and $R$ ) varying. Practically, the resonant components of class $E$ inverter will shift after the system has operated for a period of time. The load situation will also affect the resonant operation. This work will be focused on the effect of ZVS condition onto the output voltage of the system. Theoretically, the output voltage will terribly decrease as the ZVS is not achieved.

\subsection{Copper material as coupling plate}

The first material utilized in the series of experiments is copper. Copper is chosen because of its availability in the market, and also because of its position in the periodic table as among the best metals that is exist in solid type; Group 11. After being examined, the results of output voltage obtained are tabulated as in Table 3.

Table 3. Output voltage for copper up to ten sheets of paper

\begin{tabular}{ccccccccccc}
\hline Sheet of paper & 1 & 2 & 3 & 4 & 5 & 6 & 7 & 8 & 9 & 10 \\
\hline Output voltage, $\mathrm{V}_{\text {out }}(\mathrm{V})$ & 49 & 41 & 34 & 31 & 30 & 28 & 27 & 26 & 24 & 23 \\
\hline
\end{tabular}

The output voltage of the system is decreasing by the increment of the number of paper, as shown in Table 3. Besides, the particular results are also shown graphically by series of diagrams as mentioned in Figure 9, which explained the ZVS condition and the output voltage for copper. 

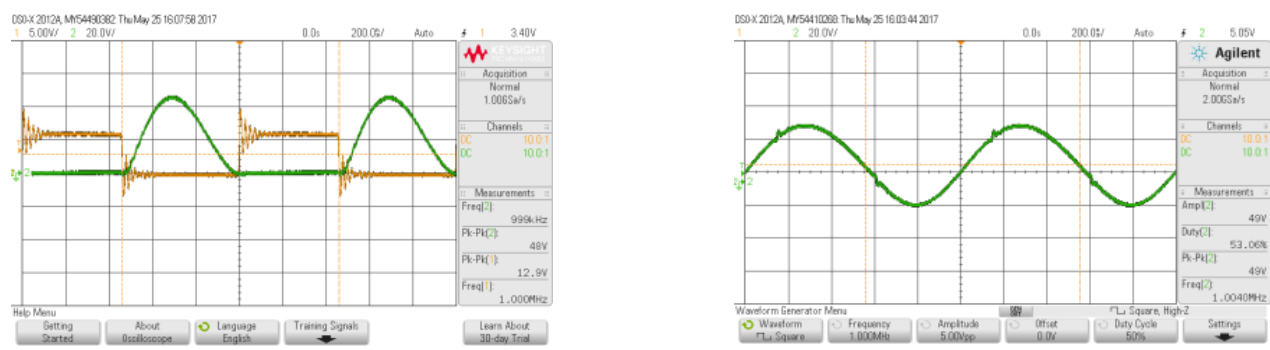

(i) 1 sheet of A4 paper
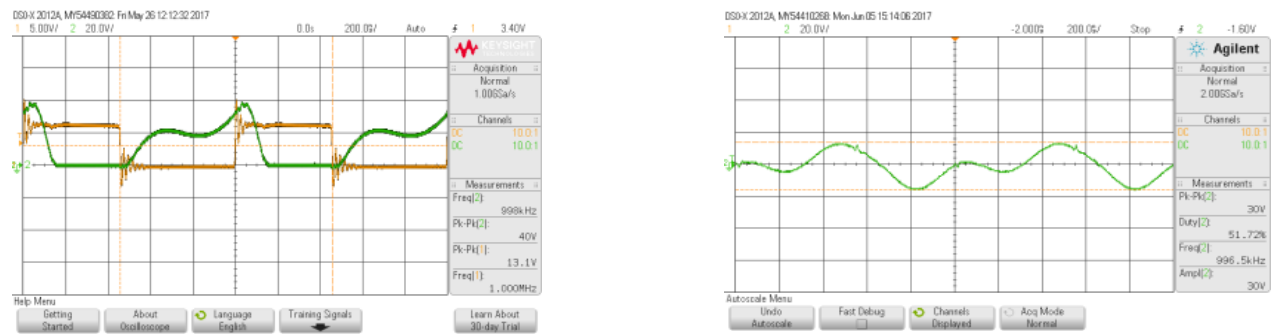

(ii) 5 sheets of A4 paper
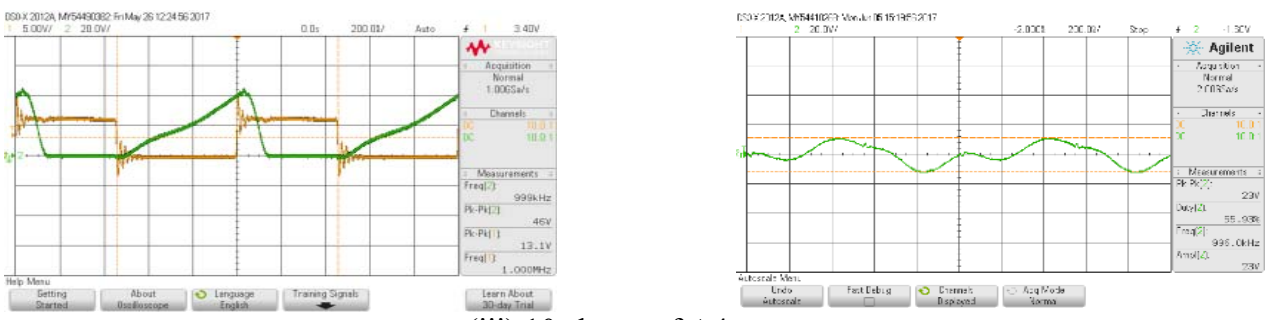

(iii) 10 sheets of A4 paper

(a) ZVS condition

(b) Output voltage

Figure 9. Series of diagrams indicating the outcomes of CPT system using copper as the capacitive plates

Figure 9 i, ii, and iii (a) indicate the ZVS condition of the Class E, and Figure 9 i, ii, and iii (b) show the output voltage of the system Based on Figure 9, the ZVS of the system is in a perfect condition when being separated by a sheet of paper only (see Figure 9 a (i)). Nevertheless, the waveforms formed are not in desired shape as the thickness of paper is increasing. Besides, the output voltage is also in desired value (more than $40 \mathrm{~V}$ ) when being separated by a sheet of paper only. As the thickness is increasing, the voltage drop is also getting higher.

Besides, the complete measurement of the output voltage over distance for copper is as shown in Figure 10. The line graph shows an exponential decrease with distance, in which as the distance is increasing, the output voltage is getting lower.

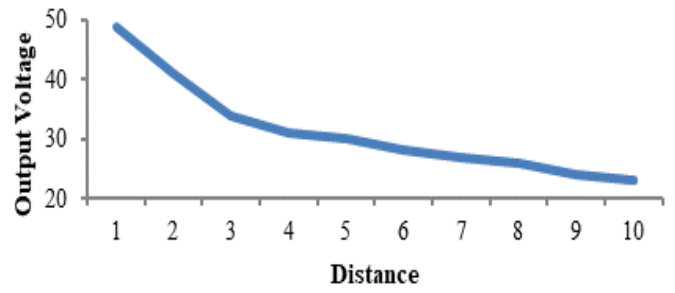

Figure 10. Exponential decrease of output voltage over distance for copper

Int J Pow Elec \& Dri Syst Vol. 11, No. 1, Mar 2020 : $200-212$ 
From Figure 10 it can be clarified that the initial voltage reading of $49 \mathrm{~V}$ has decreased tremendously as the distance is larger, hence the lowest output voltage resulted for 10 sheets of papers which is around $23 \mathrm{~V}$. Thus, the results formed by using copper as the capacitive plates are reliable as power can still be transferred wirelessly even the gap distance is getting higher.

\subsection{Zinc material as coupling plate}

The second material which has been used in the experimental work is zinc. Same as copper, zinc is chosen because of its availability in the market in metal sheet form, and the position in the periodic table of elements. Zinc is located in Group 12 which has lower metal strength yet comparable to copper. The results of output voltage produced by zinc capacitive plates are tabulated in Table 4.

Table 4. Output voltage for Zinc up to ten sheets of paper

\begin{tabular}{lllllllllll}
\hline Sheet of paper & 1 & 2 & 3 & 4 & 5 & 6 & 7 & 8 & 9 & 10 \\
\hline Output voltage, $\mathbf{V}_{\text {out }}(\mathbf{V})$ & 47 & 44 & 42.2 & 40 & 36 & 35 & 32 & 31 & 30 & 27 \\
\hline
\end{tabular}

By referring Table 4, it can be seen that the output voltage of zinc is decreasing consistently as the sheets of paper is increasing. Moreover, series of diagrams in Figure 11 are the experimental results in terms of the ZVS condition and the output voltage for zinc as the capacitive plates.
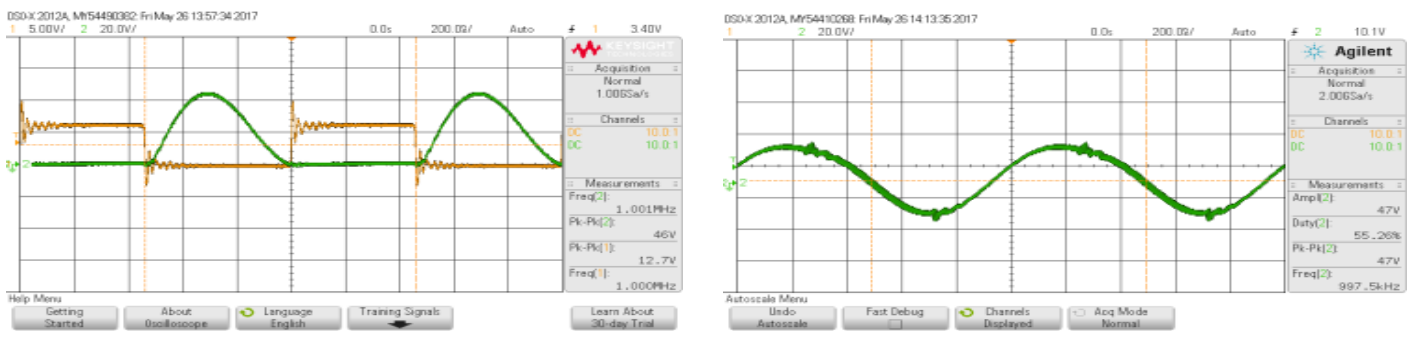

(i) 1 sheet of A4 paper
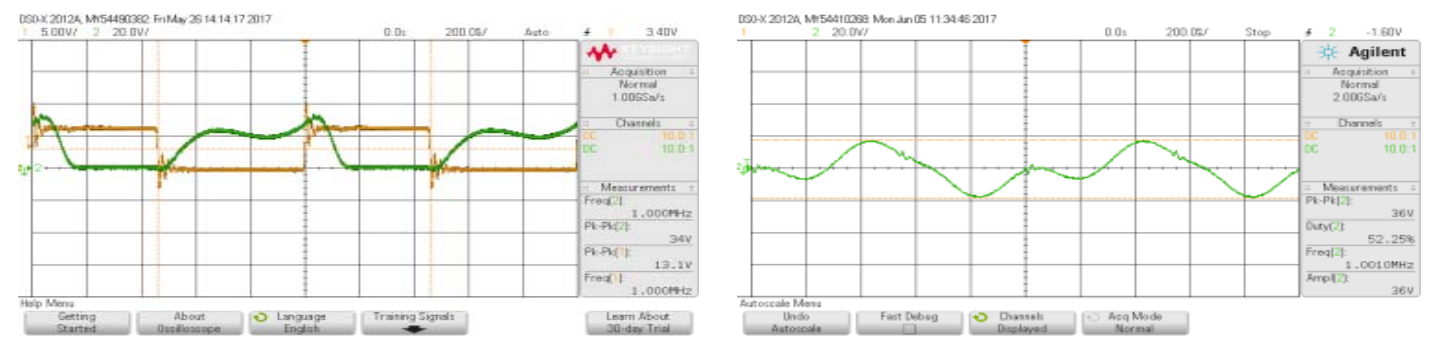

(ii) 5 sheets of A4 paper
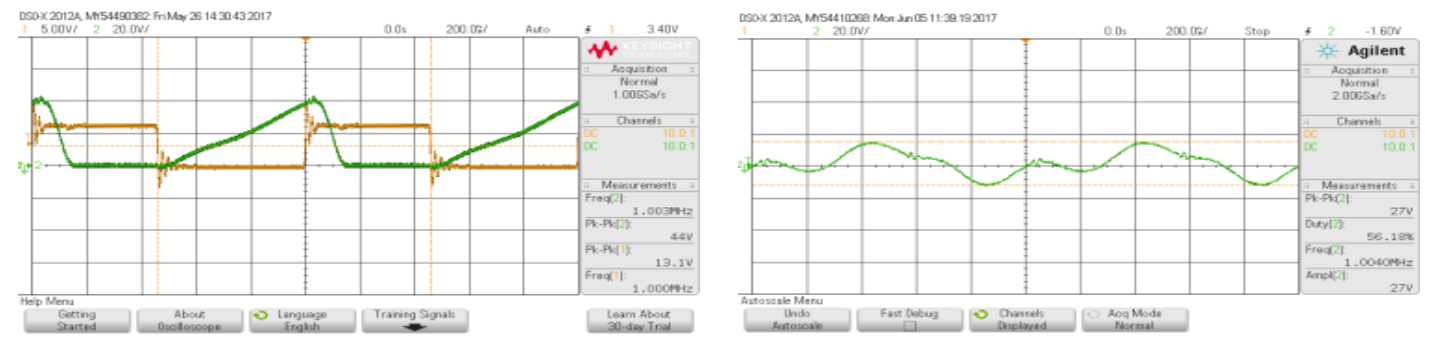

(iii) 10 sheets of A4 paper

(a) ZVS condition

(b) Output voltage

Figure 11. Series of diagrams indicating the outcomes of CPT system using zinc as the capacitive plates 
Figure 11 i, ii, and iii (a) show the ZVS condition for 1,5 , and 10 sheets of paper respectively. While Figure 12 i, ii, and iii (b) show the output voltage for the experiment. By referring to Figure 11, the perfect desired waveforms are achieved by Figure 11 (i) which indicates the zero-voltage-switching condition and the output voltage for one sheet of paper. As the distance is increasing, the output voltage becoming undesirable even the reading can still be recorded, as the ZVS is not achieved. As mentioned in previous section, ZVS is the most important property of class E since it determines the efficiency of the system. Besides, Figure 12 shows the complete measurement of the output voltage over distance for zinc as the capacitive plates. The graph shows a linear decrease of output voltage with increasing distance.

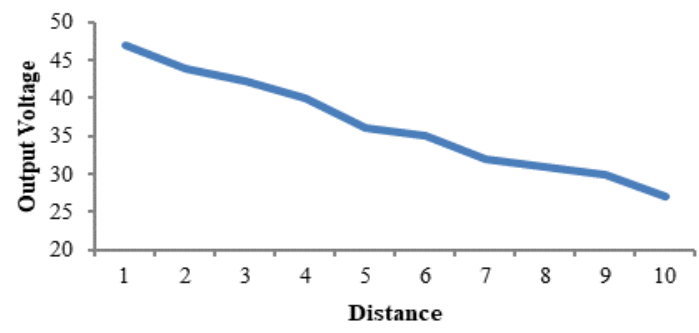

Figure 12. Linear decrease of output voltage over distance for zinc

From Figure 12, it can be shown that the initial voltage reading of around $47 \mathrm{~V}$ has decreased linearly as the distance is larger. The lowest output voltage resulted for 10 sheets of paper which is around $26 \mathrm{~V}$. Based on the graph even it is linearly decrease, the rate of decrement is not as smooth as shown by graph of copper in Figure 10. One of the factors of this phenomenon is because of the position of zinc which is in Group 12 of periodic table of elements. The elements in this group have weaker metal characteristics as compared to elements in Group 11 which represents the position of copper.

\subsection{Aluminium material as coupling plate}

Among those three materials used, aluminium is categorized as poor metal element and is available in Group 13 in the periodic table. This means that the metal characteristic shown by aluminium is the weakest among all. Besides the availability in the market in terms of sheet form, this is the reason of choosing aluminium as it is comparable to zinc and copper. After done the same procedure as copper and zinc, output voltage yield from the experiment is tabulated as in Table 5.

Table 5. Output voltage of aluminium up to 10 sheets of paper

\begin{tabular}{lllllllllll}
\hline Sheet of paper & 1 & 2 & 3 & 4 & 5 & 6 & 7 & 8 & 9 & 10 \\
\hline Output voltage, $\mathrm{V}_{\text {out }}(\mathrm{V})$ & 45.8 & 43 & 39 & 36 & 35 & 33 & 30 & 25 & 23 & 21 \\
\hline
\end{tabular}

The output voltages of aluminium CPT system keep lessening from 45.8V of one sheet of paper, until $21 \mathrm{~V}$ for 10 sheets of paper as shown in Table 5. This indirectly tells us that the output power is also keep declining from one sheet to ten sheets of paper. Moreover, series of diagrams in Figure 13 explains in details regarding the performance of the system in terms of ZVS condition and output voltage.

Figure 13 i, ii, and iii (a) shown the ZVS condition of the system, while Figure $13 \mathrm{i}$, ii, and iii (b) are the output voltage of the system. From Figure 13, Figure 13i (a) and (b) indicate the ideal situation of ZVS condition and the output voltage of the system. As the gap distance is increasing, the outcomes changed to non-ideal conditions. From these, authors are certain about the results which are aligned with the theory of class E CPT system in which the output power of a system will be worsening if the ZVS condition is not achieve. Besides, Figure 14 shows the complete measurement of the output voltage over distance for aluminium as the capacitive plates in graph. The graph shows a linear decrease by distance. 


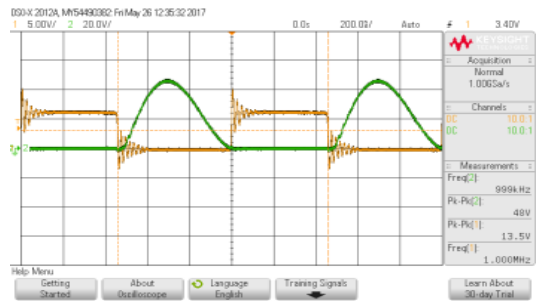

(i) 1 sheet of A4 paper
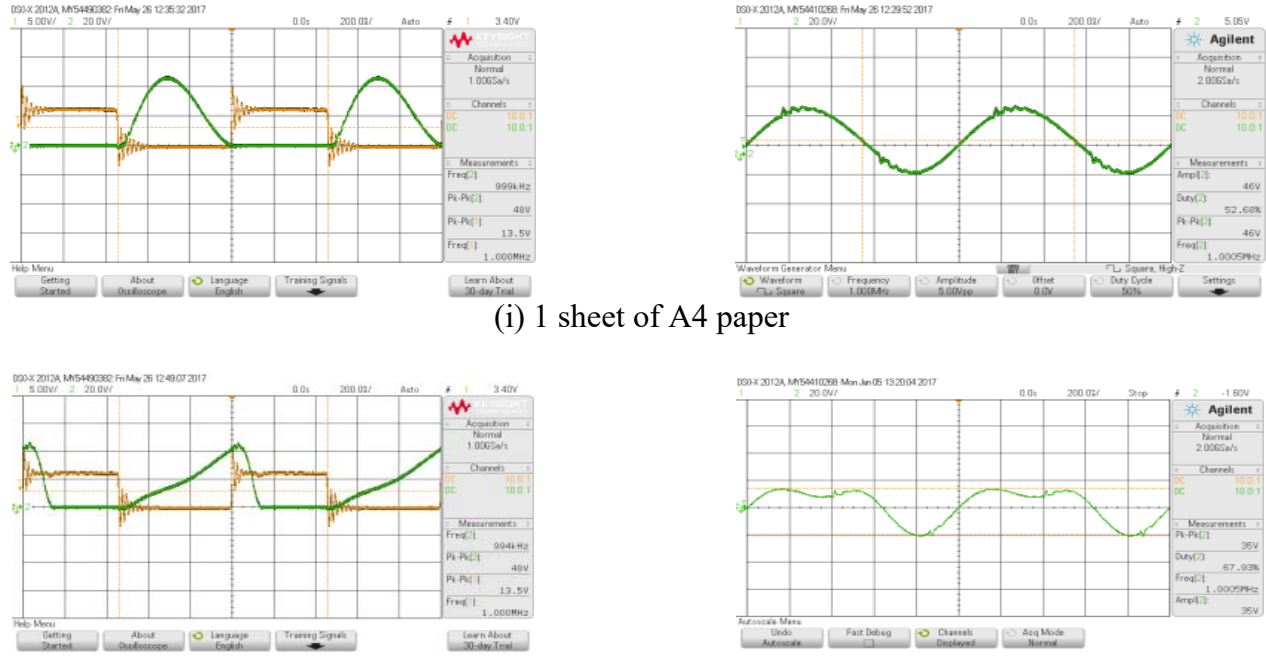

(ii) 5 sheet of A4 paper
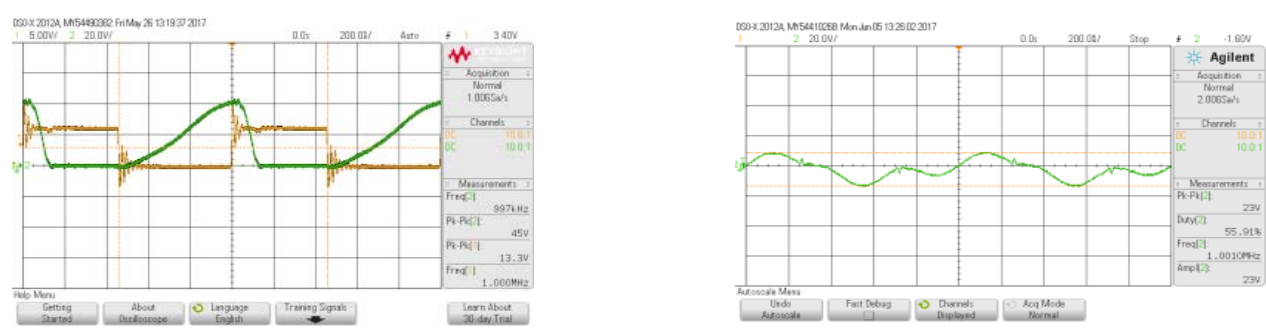

(iii) 10 sheet of A4 paper

(a) ZVS condition

(b) Output voltage

Figure 13. Series of diagrams indicating the outcomes of CPT system using aluminium as the capacitive plates

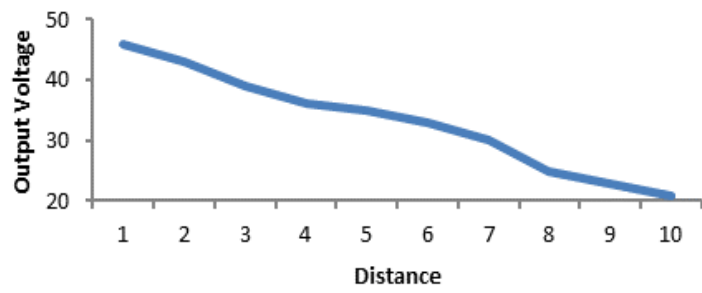

Figure 14. Linear decrease of output voltage over distance for aluminium

The initial output voltage reading of $45.5 \mathrm{~V}$, as shown in Figure 14, has continuous linear decrease as the distance is increased, which resulted lower output voltage resulted for 10 sheet of papers which is around $21 \mathrm{~V}$. Same as zinc, the graph line of this aluminium is not as smooth as resulted from copper because aluminium is classified under poor metal category in the periodic table of elements [25].

\subsection{Material comparison for better implementation of CPT circuit}

In a nutshell, based on the outcomes of the experiment, it can be concluded that all of the materials used in the experiments produced similar results. However, when being compared in details, the line graph of copper which shows an exponential decrease is more reliable than line graphs made by zinc and aluminium. This is aligned with the position of each material in the periodic table of elements in which copper and zinc is categorized under transition metals whilst aluminium is placed under the poor metals category. Since copper is placed in Group 11 and zinc is in Group 12 of the periodic table, copper shows better metal characteristics 
especially in terms of output voltage as compared to zinc which has lower quality of metal characteristics as it is placed in Group 12. Therefore, it can be concluded that among these three materials, copper has the best quality in terms of implementation as capacitive plates, though all of them have potential to be the plates.

\section{CONCLUSION}

This paper explains the implementation of different materials as an alternative to act as the capacitive plates. The materials particularly aluminium, copper, and zinc, shown promising results and aligned with the theory of periodic table of elements. Generally, the value of output voltage is decreased as the gap distance between the plates is increased. The output voltage resulted from copper is better than zinc and aluminium since among these three materials, copper and zinc are classified as the transition metals but in different groups, whereas aluminium is in poor metal group. In future, adding a self-tuning circuit is a great improvement to enhance the system, especially in hardware implementation since the circuit added enables the output power to be increased firmly with suitable values and system.

\section{ACKNOWLEDGEMENTS}

We would like to express our gratitude to Universiti Teknikal Malaysia Melaka for providing such great facilities to deliver this work. The gratitude also belongs to Ministry of Education (MoE) through Fundamental Research Grant Scheme (FRGS) with grant number of FRGS/1/2016/TK04/FKEKKCeTRI/F00313.

\section{REFERENCES}

[1] D. Rozario, S. Member, N. A. Azeez, S. S. Williamson, and S. Member, "Analysis and Design of Coupling Capacitors for Contactless Capacitive Power Transfer Systems," 2016.

[2] S. Asheer, A. Al-marwani, T. Khattab, and A. Massoud, "Contactless Power and Data Transfer for Electric Vehicle," vol. 2, no. 7, pp. 3164-3173, 2013.

[3] E. Waffenschmidt and T. Staring, "Limitation of inductive power transfer for consumer applications," Power Electron. Appl. 2009. EPE '09. 13th Eur. Conf., pp. 1-10, 2009.

[4] T. Zaid, S. Saat, Y. Yusop, and N. Jamal, "Contactless energy transfer using acoustic approach - A review," I4CT 2014 - 1st Int. Conf. Comput. Commun. Control Technol. Proc., no. I4ct, pp. 376-381, 2014.

[5] T. Zaid, S. Saat, N. Jamal, S. H. Husin, and Y. Yusof, "Implementation of a MIMO System for Wireless Power Transfer Using Acoustic Approach," International Journal of Power Electronics and Drive System (IJPEDS), vol. 7, no. 3, pp. 938-945, 2016.

[6] Huzaimah Husin, Yusmarnita Yusop, Shakir Saat, and S. K. Nguang, "Development of 416kHz PZT Driver for Acoustics Energy Transfer applications," no. March, pp. 4-6, 2016.

[7] C. Xia, Y. Zhou, J. Zhang, and C. Li, "Comparison of power transfer characteristics between CPT and IPT system and mutual inductance optimization for IPT system," J. Comput., vol. 7, no. 11, pp. 2734-2741, 2012.

[8] K. Kh., S. Saat, Y. Yusmarnita, M. S. Ramli, and A. W. S. Sufiah, "Capacitive power transfer (CPT) system design using a class e resonant converter circuit," AIP Conf. Proc., vol. 1705, 2016.

[9] B. Ge, S. Member, C. Ludois, and R. Perez, "The Use of Dielectric Coatings in Capacitive Power Transfer Systems," pp. 2193-2199, 2014.

[10] N. Jamal, S. Saat, Y. Yusmarnita, T. Zaid, and A. Isa, "Investigations on Capacitor Compensation Topologies Effects of Different Inductive Coupling Links Configurations," International Journal of Power Electronics and Drive System (IJPEDS), vol. 6, no. 2, 2014.

[11] K. N. Mude, M. Bertoluzzo, G. Buja, and L. Fellow, "Inductive Characteristics of Different Coupling Setups for Wireless Charging of an Electric City-Car," pp. 1-7, 2014.

[12] M. G. L. Roes, J. L. Duarte, M. A. M. Hendrix, and E. A. Lomonova, “Acoustic energy transfer: A review," IEEE Trans. Ind. Electron., vol. 60, no. 1, pp. 242-248, 2013.

[13] A. Mediano and N. O. Sokal, "A Class-E RF Power Amplifier with a Flat-Top Transistor-Voltage Waveform," IEEE Trans. Power Electron., vol. PP, no. 99, p. 1, 2013.

[14] F. Lu, H. Zhang, H. Hofmann, and C. Mi, "A Double-Sided LC Compensation Circuit for Loosely-Coupled Capacitive Power Transfer," IEEE Trans. Power Electron., vol. 8993, no. c, pp. 1-1, 2017.

[15] S. J. Huang, T. C. Hung, and S. Y. Liu, "Combination of class e inverters with DC-DC converters for a circuit design with controllable dual outputs," Proc. IEEE Int. Conf. Ind. Technol., vol. 2015, no. June, pp. 957-962, 2015.

[16] N. Keskin and H. Liu, "Complementary Class-E Amplifier for Wireless Power Transfer," pp. 2235-2240, 2015.

[17] D. Rozario, "Design of Contactless Capacitive Power Transfer Systems for Battery Charging Applications," University of Ontario Institute of Technology, 2016.

[18] Y. Yusop, S. Saat, Z. Ghani, H. Husin, and S. K. Nguang, "Capacitive power transfer with impedance matching network,” 2016 IEEE 12th Int. Colloq. Signal Process. Its Appl., no. March, pp. 124-129, 2016.

[19] Y. Yusop, et al., "A study of capacitive power transfer using class-e resonant inverter," Asian J. Sci. Res., vol. 9, no. 5, pp. 258-265, 2016.

Int J Pow Elec \& Dri Syst Vol. 11, No. 1, Mar 2020 : $200-212$ 
[20] Y. Yusop, S. Saat, S. K. Nguang, H. Husin, and Z. Ghani, "Design of Capacitive Power Transfer Using a Class-E Resonant Inverter," vol. 16, no. 5, pp. 1678-1688, 2016.

[21] C. Carroll, C. Liam, R. Gerry, C. Ludlow, "Trade of Electrician," in Electrical Course Notes- Unit 2.1.8, no. 4, SOLAS, pp. 1-48, 2013.

[22] F. K. A. Rahman, S. Saat, Y. Yusop, S. H. Husin, and S. Ludin, "Simulation-based Study of Capacitance Values Affected by Various Dielectric Materials and Distances for Low Power Wireless Power Transfer System," 2016.

[23] K. Maex, M. R. Baklanov, D. Shamiryan, F. Iacopi, S. H. Brongersma, and Z. S. Yanovitskaya, "Low dielectric constant materials for microelectronics," J. Appl. Phys., vol. 93, no. 11, pp. 8793-8841, 2003.

[24] F. K. A. Rahman, S. Saat, L. H. Zamri, N. M. Husain, N. A. Naim, and S. A. Padli, "Design of Class-E Rectifier with DC-DC Boost Converter," vol. 8, no. 1, pp. 89-95, 2016.

[25] Marian K. Kazimierczuk and C. Dariusz, Class E Zero Voltage Switching Resonant Inverter. 2011.

[26] N. O. Sokal and A. D. Sokal, "Class E-A new class of high-efficiency tuned single-ended switching power amplifiers," IEEE J. Solid-State Circuits, vol. 10, no. 3, pp. 168-176, 1975.

[27] Marian K. Kazimierczuk, RF Power Amplifiers, First edit. John Wiley \& Sons, Ltd, 2008.

[28] Y. F. Li and S. M. Sue, "Exactly analysis of ZVS behavior for class e inverter with resonant components varying," Proc. 2011 6th IEEE Conf. Ind. Electron. Appl. ICIEA 2011, pp. 1245-1250, 2011.

[29] Z. Xu, Z. Yang, and J. Zu, "Impedance matching circuit for synchronous switch harvesting on inductor interface," 2015 IEEE Int. Conf. Mechatronics Autom. ICMA 2015, no. 1, pp. 341-345, 2015.

[30] J. Kim, D. H. Kim, and Y. J. Park, "Analysis of Capacitive Impedance Matching Networks for Simultaneous Wireless Power Transfer to Multiple Devices," IEEE Trans. Ind. Electron., vol. 62, no. 5, pp. 2807-2813, 2015.

[31] J. Millán, "Wide band-gap power semiconductor devices," Circuits, Devices Syst. IET, vol. 1, no. 5, pp. 372-379, 2007.

\section{BIOGRAPHIES OF AUTHORS}
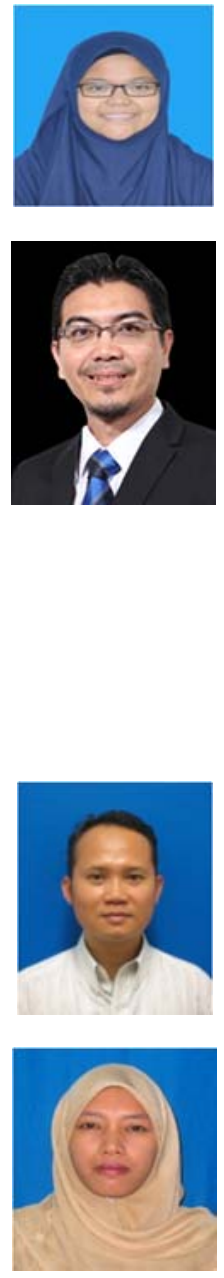

F.K.A Rahman was born in Kuala Lumpur, Malaysia in 1992. She obtained her Bachelor Degree in Applied Physics from Universiti Sains Islam Malaysia (USIM), Negeri Sembilan, Malaysia in November 2015. She had her internship at Significant Technologies Sdn Bhd for five months until June 2015 before pursuing her Masters Degree in Electronic Engineering at Universiti Teknikal Malaysia Melaka, UTeM since September 2015. Her research field includes wireless power transfer system specifically in capacitive power transfer.

S. Saat was born in Kedah, Malaysia in 1981. He obtained his bachelor degree in Electrical Engineering from Universiti Teknologi Malaysia and Master in Electrical Engineering from the same university in 2002 and 2006, respectively. Furthermore, he obtained his $\mathrm{PhD}$ in Electrical Engineering from The University of Auckland in the field of nonlinear control theory in 2013. He started his carrier as a lecturer at Universiti Teknikal Malaysia Melaka in 2004 and he is now an Associate Professor and Dean at Faculty of Electronic and Computer Engineering of the same university. His research interest is on nonlinear systems control theory and wireless power transfer technologies. He has published one book (published by springer verlag) on polynomial control systems and more than 50 journals and mostly published in the high quality journal such as The Journal of the Franklin Institute, International Journal of Robust and Nonlinear Control, IET Control and etc. More than 30 conference papers have also been published and most of them are in the framework of nonlinear control theory and wireless power transfer technologies. He is also appointed as a reviewer for IEEE Transaction journals, The journal of system science, The Journal of the Franklin Institute, International Journal of Robust and Nonlinear Control, Circuit, systems and signal processing and many more.

A.Khafe received the B.Eng (2000) from Multimedia University, M.Eng (2005) from Kolej Universiti Tun Hussein Onn, Malaysia respectively. First appointed as Engineering Instructor (2004) at Kolej Universiti Teknikal Malaysia Melaka and promoted as Lecturer (2005) and Senior Lecturer (2008) in the Department of Industrial Electronics, Faculty of Electronic and Computer Engineering at Universiti Teknikal Malaysia MelakaHe is now lecturer at the same department.

Y. Yusop was born in Melaka, Malaysia in 1979. She received the B. Eng in Electrical Engineering (Mechatronic) from Universiti Teknologi Malaysia, in 2001, the M. Eng degree in Electrical Engineering from Kolej Universiti Tun Hussein Onn, Malaysia, in 2004 and Ph. D degree in Electrical Engineering (Capacitive Power Transfer) from Universiti Teknikal Malaysia Melaka in 2018. Her career as academician begins in 2005 as a Teachhing Engineer at Department of Industrial Electronic, Technical University Malaysia Malacca and now she is a Senior Lecturer at the same university. Her area of research interests includes electronic system design, wireless power transfer and power electronics. 


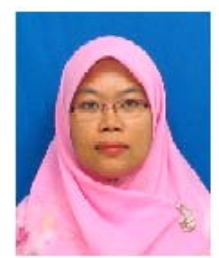

S. H. Husin received the B.Eng (2000) from Multimedia University, M.Eng (2005) from Kolej Universiti Tun Hussein Onn, Malaysia respectively. First appointed as Engineering Instructor (2001) at Kolej Universiti Teknikal Malaysia Melaka and promoted as Lecturer (2005) and Senior Lecturer (2008) in the Department of Industrial Electronics, Faculty of Electronic and Computer Engineering at Universiti Teknikal Malaysia Melaka. Since September 2014, she pursuing PhD in Advanced Control Technology that focused on acoustics energy transfer.

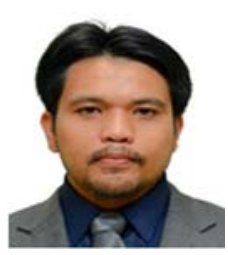

M. H. JAMALUDDIN received bachelor's and master's degrees in Electrical Engineering from Universiti Teknologi Malaysia (UTM), Malaysia, in 2003 and 2006, respectively, and the Ph.D. degree in signal processing and telecommunications from the Université de Rennes 1, France, in 2009 , with a focus on microwave communication systems and specially antennas such as dielectric resonator and reflectarray and dielectric dome antennas. He is currently an Associate Professor with the Wireless Communication Centre, School of Electrical Engineering, Universiti Teknologi Malaysia. His research interests include dielectric resonator antennas, printed microstrip antennas, MIMO antennas and DRA reflectarray antenns. He has published more than 100 papers in reputed indexed journals and conference proceedings

Int J Pow Elec \& Dri Syst Vol. 11, No. 1, Mar 2020 : $200-212$ 